\title{
LASER COMMUNICATIONS PROTOTYPING FOR THE GROUP OF MOBILE ROBOTS
}

\author{
Valentin Pryanichnikov \& Daria Stepanova
}
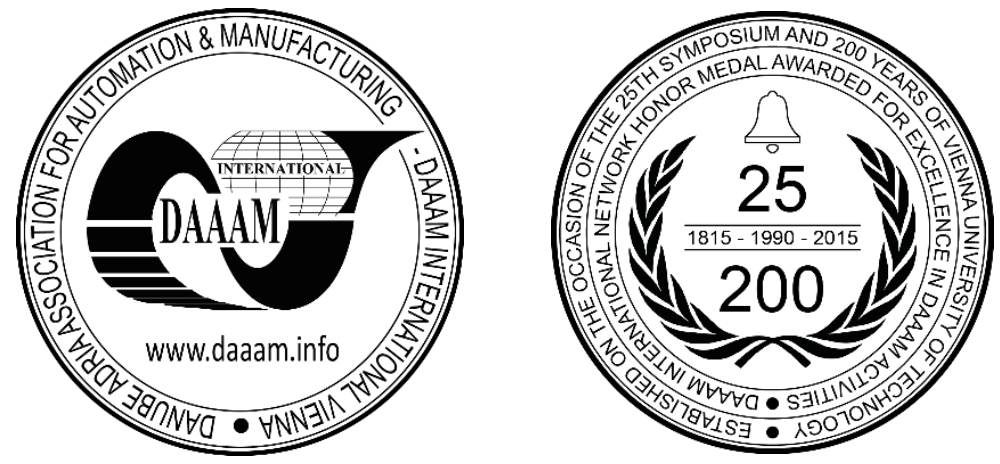

This Publication has to be referred as: Pryanichnikov, V[alentin] \& Stepanova, D[aria] (2016). Laser Communications Prototyping for the Group of Mobile Robots, Proceedings of the 27th DAAAM International Symposium, pp.0544-0550, B. Katalinic (Ed.), Published by DAAAM International, ISBN 978-3-902734-08-2, ISSN 1726-9679, Vienna, Austria DOI: $10.2507 / 27$ th.daaam.proceedings.080

\begin{abstract}
Laser communications in case of a group of mobile robots communication in extreme conditions can be considered as an alternative or supplement to the radio. Thus, this work aims to develop a laser communication terminal for a mobile robot and with the particular focus on building the pointing, acquisition and tracking (PAT) system. During the present work, the idea of the laser terminal design was proposed based on the analysis of requirements and the model of data transmission between two mobile robots. The mathematical model of the PAT control system and stability analysis showed the feasibility of the design. A separate part of the work was also dedicated to the development of the robot orientation determination system and PAT stabilization system. The prototype and all necessary algorithms were implemented and the hardware and software were created. At this point, the laser terminal has been tested and has achieved acceptable performance of 5 degrees of accuracy under existing constraints. The paper was partially supported by the Russian Foundation for Basic Research, project No. 16-07-01264a, 16-07-00935a, 16-07-00811a.
\end{abstract}

Keywords: Mobile robots optical communications; guidance system; pointing and tracking.

\section{Introduction}

The performance of radio frequency $(\mathrm{RF})$ communications is noticeably weaker than the one of optical in a number of applications [1]. Comparing to RF communication, optical links provide larger modulation bandwidth, therefore higher communication speed and higher security level due to less interference between the optical signals. [2] A higher optical antenna directivity and thus, a higher concentration of energy in the laser beam, makes the gain of optical antennas higher than that of the RF with the same efficiency. RF antennas can possibly achieve the same order of directivity, however, the aperture will increase proportionally with the gain affecting the weight of antenna as well [3], becoming impossible to be used on small robots. The advantage of high directivity in optical antennas brings the challenge of accurate pointing for the optical beam [4]. The importance of pointing, acquisition and tracking (PAT) system considerably increases due to the sensitivity of communication speed on pointing accuracy: the lower the accuracy the more link losses will happen during the communication session, less information will be transmitted [5]. Important parameters such as beam divergence and transmitter power depend on pointing accuracy as well and thus, influence the laser terminal design. The lower the pointing accuracy, the higher the beam divergence shall be, the more transmit power shall be used to provide the same 
communication speed. The aim of this work is to develop a laser terminal and PAT systems for the experimental laser communication testing between two or more mobile robots [6-18].

\section{Possible configurations for the group of mobile robots}

During present work, several possible configurations of mobile robots operating in a hazardous area and connections between them were considered. Each configuration is based on the following assumptions: a group of mobile robots collects information in a hazardous area and transmits the data about the zone and telemetry through an unmanned aerial vehicle (UAV) working as a relay to a station controlled by people and located outside the danger zone.

Thus, the optical communication link may be established between:

1 - mobile robots; 2 - mobile robots and relay; 3 relay and a repeater station.

Each scenario assumes the development of optical terminal that meets certain specific requirements in each case.

\section{System Design}

Requirements definition for the design of complex optical and PAT systems is the key to successful performance of the whole optical terminal. The following requirements for the terminal design were derived during present work.

The data transfer rate. To determine the requirements for data rates the amount of data produced by the mobile robot have been evaluated. In most cases, in hazardous locations where people prefer mobile robots to perform all necessary operations, people shall be aware of the place where the robot operates. Therefore, the main type of transmitted information is a real time video; thus, the upper bound of data rate was chosen to be $150 \mathrm{Mbs}$.

The distance between mobile robots. Within all possible configurations in which the mobile robot can operate in extreme conditions, the distance between robots, robots to the repeater and the repeater to the station can vary from $10 \mathrm{~m}$ to several kilometres. Thus, the upper bound of the distance was chosen to be $3 \mathrm{~km}$.

The size of the optical terminal. The size of an optical terminal, which is located on the mobile robot, is a critical parameter. Thus, during the present work the compromise between the size, weight and terminal requirements in terms of "endurance" was chosen. One of the main factors limiting the miniaturization of the optical terminal is the telescope, which was chosen to be the Newton telescope.

Other requirements for the laser are shown in Table 1.

\begin{tabular}{|l|l|l|l|}
\hline Parameter & Value & Parameter & Value \\
\hline Power at the transmitter & $0.5 \mathrm{~W}$ & Mirror mass & $165 \mathrm{~g}$. \\
\hline Laser wavelength & $1550 \mathrm{~nm}$ & Mirror size & $200 x 85 \mathrm{~mm}$ \\
\hline Distance between mobile robots & $3 \mathrm{~km}$ & Maximum beam divergence & $3 \mathrm{deg}$ \\
\hline Terminal mass & $<3 \mathrm{~kg}$ & PAT system mass & $400 \mathrm{~g}$. \\
\hline
\end{tabular}

Table 1. Parameters and requirements for laser terminal design

Requirements definition based on the mathematical model. In order to determine the requirements and the parameters for the optical communication terminal and to choose necessary technical equipment for its implementation a mathematical model of the motion of mobile robots and optical channel model were developed. Due to the fact that the mutual movement of mobile robots is arbitrary, several scenarios of their relative motion were considered. Figures below show the trajectories of the oncoming traffic two robots on a path in the form of a square (Fig.1) and on a collision trajectory (Fig.2) together with the change of relative angle (second plot) and the corresponding power changes (third plot). 

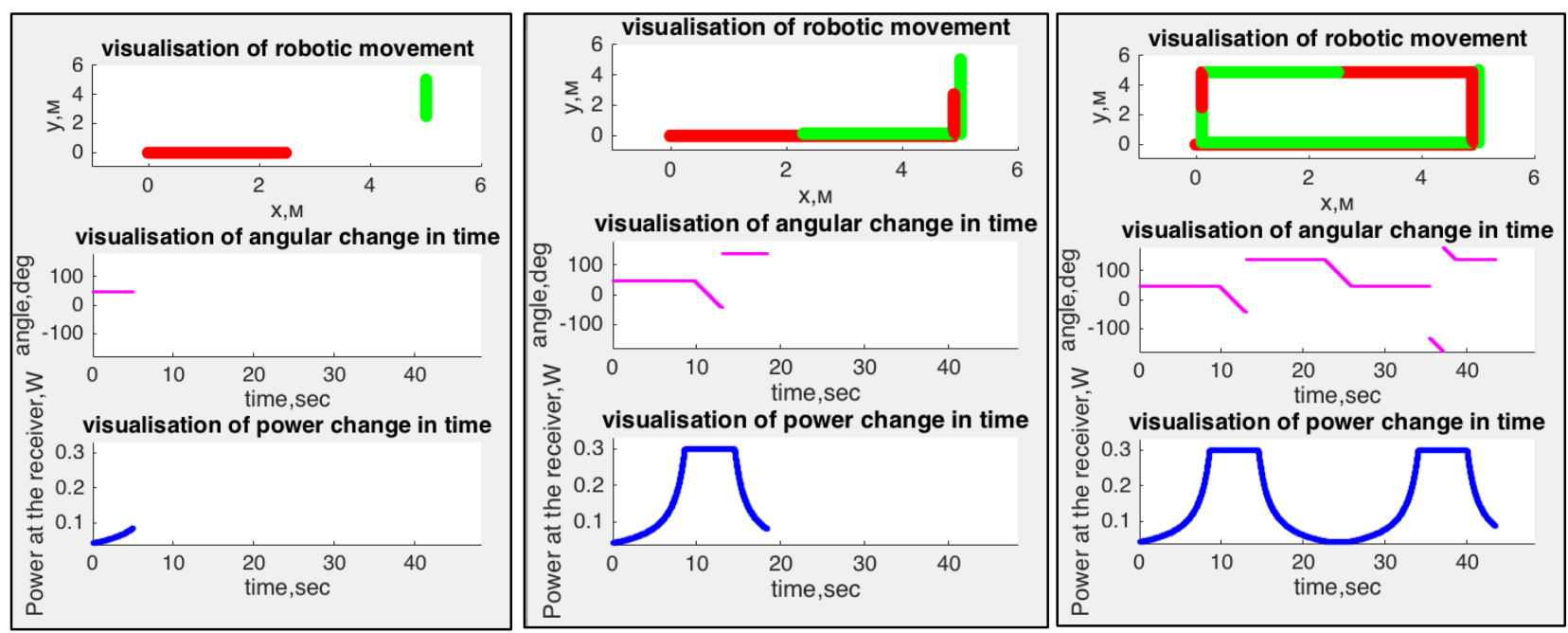

Fig.1. Mobile robots simulation of motion in opposite directions for 3 different points at time for the trajectory "line"
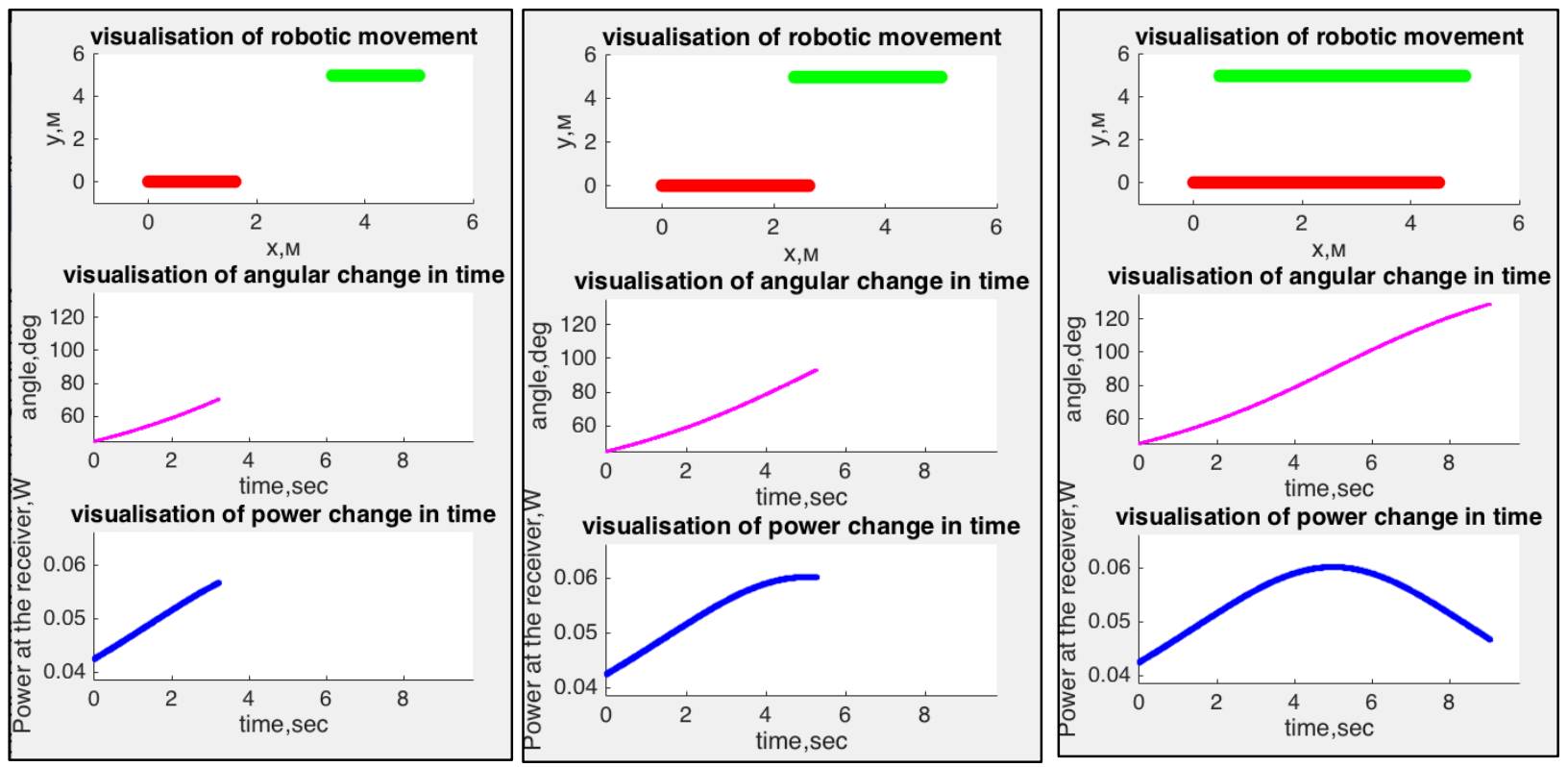

Fig.2. Mobile robots simulation of motion in opposite directions for 3 different points at time for the trajectory "rectangle"

Following parameters varied during the simulation: the width of the optical beam, tracking accuracy, transmitter power, the distance between mobile robots. As a result, critical angular rates, delays in the tracking algorithm were estimated. Some variations of parameters in different scenarios are listed in Table 2.

\begin{tabular}{|l|l|l|l|}
\hline Parameter & 1 Scenario & 2 Scenario & 3 Scenario \\
\hline Trajectory type & $\begin{array}{l}\text { Robots move towards } \\
\text { each other on two lines } \\
\text { with 5m difference } \\
\text { between them. }\end{array}$ & $\begin{array}{l}\text { Robots move towards } \\
\text { each other on two lines } \\
\text { with 50m difference } \\
\text { between them. }\end{array}$ & $\begin{array}{l}\text { Robots move towards each } \\
\text { other on two lines with } \\
500 \mathrm{~m} \text { difference between } \\
\text { them. }\end{array}$ \\
\hline $\begin{array}{l}\text { Optical beam divergence, } \\
\text { deg }\end{array}$ & 1 & 2 & 3 \\
\hline Power at the receiver, W & 0.01 & 0.1 & 0.54 \\
\hline Angular rates, deg/sec & $5.7-11.4$ & $0.5-1.1$ & $0.068-0.057$ \\
\hline Max algorithm delay, sec & 0.086 & 1.71 & 15.67 \\
\hline
\end{tabular}

Table 2. Parameter comparison depending on scenario 


\section{Tracking algorithm development}

After the connection establishment, the question of its retention and communication quality improvement by compensating for pointing errors appears. For that purpose, the tracking algorithm was developed based on the image processing of the laser spot captured by the CMOS matrix with the size of 460x640 pixels. At this stage of project, the image-processing algorithm is performed on a PC using Matlab program. The developed algorithm allows the detection of an optical spot with other objects on the background, including radiant, determination of the distance between robots based on the spot size and calculation the pointing vector for the control system. Fig. 3 shows examples of the algorithm results.

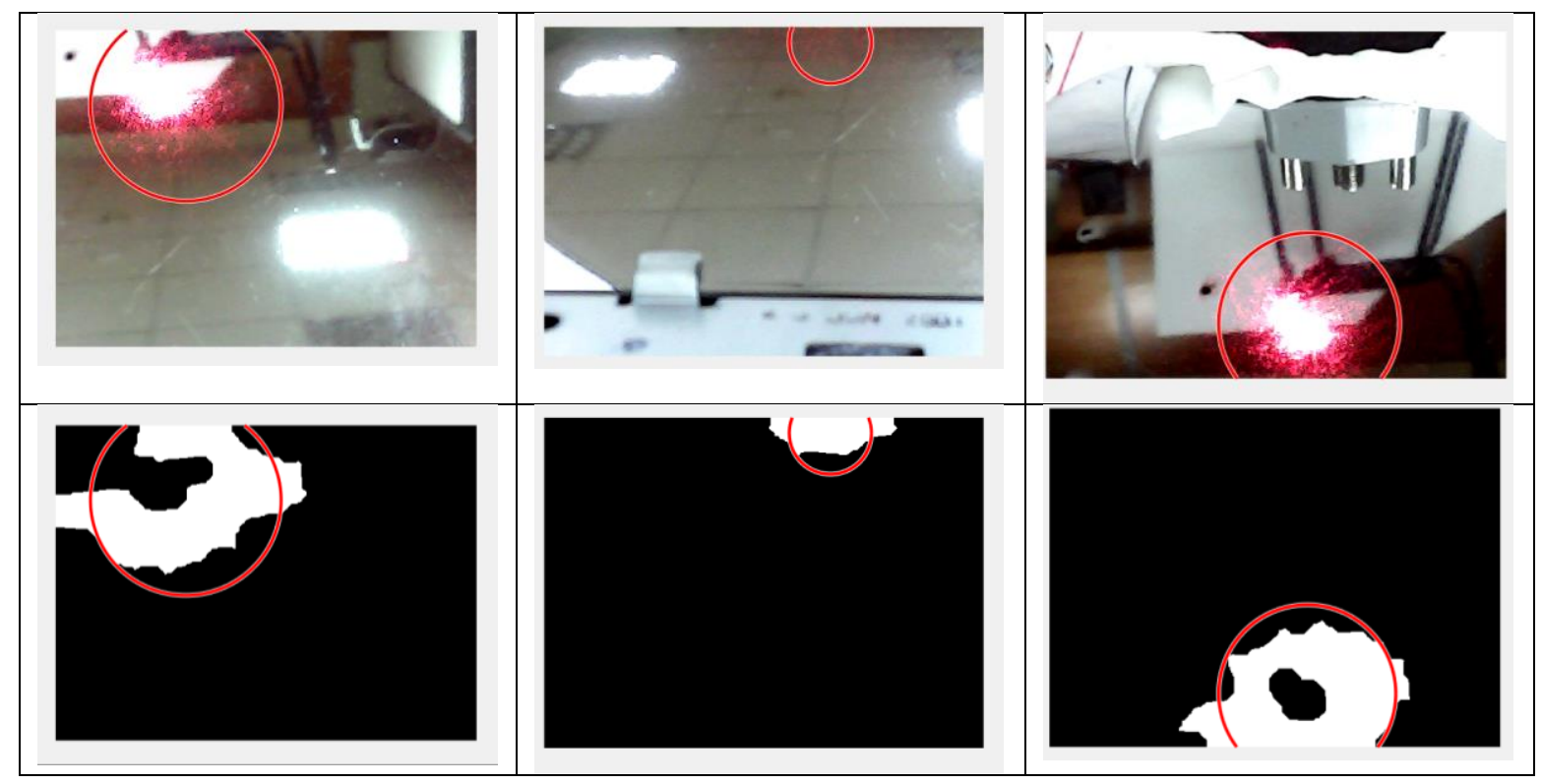

Fig.3 Tracking algorithm development

The algorithm processing time is 0.13 seconds with 7 frames per second, which is not enough for some configurations of mobile robots. However, in future it is planned to optimize the algorithm and implement it on the FPGA, thereby reducing the calculation time to 0.002 seconds.

\section{The laser terminal prototype development}

After the requirements analysis and optical terminal mathematical model development, the laser terminal was designed with an emphasis on the low-cost component selection. The terminal consists of the following subsystems: optical, electrical, PAT system.

The optical subsystem is represented by the telescope, PAT mirror, lenses, and splitter, which are connected to redirect the optical beam to the receiver and CCD matrix. The laser beam way in the optical system is following: on the receiving side the plane optical wave falls on a mirror of the PAT system. The mirror redirects the optical signal to the main telescope. Here, the optical beam is divided into two by the splitter. Most of the beam falls on an avalanche photodiode, and the rest focuses on the CCD matrix to collect information about the pointing error. This information is used as feedback to the PAT system. The transmitting part consists of a photodiode, the lens, which is necessary for the calibration of the beam divergence, and is mounted on the PAT system.

Electronics and software. The electronic subsystem is divided into the analog signal recovery, which strengthens and purifies raw optical signals, and a digital processing of packages. The redundant communication channel is also present on the platform and is based on the Xbee long-range transceivers. The basic system software is implemented on a microcomputer BeagleBone Black. It runs the basic software: the position forecast, laser and radio transmitter, communication control I2C, part of the PAT software.

The aim of PAT system is to provide the best possible pointing accuracy of the optical beam. The approach for the PAT system design is following: the laser diode and the main mirror of the optical system, which redirects the optical beam in the telescope, rotate in two planes - pitch and yaw. The mirror and laser are mounted on a horizontal axis of rotation; frame is mounted on a mobile platform. PAT system includes a sensor subsystem that is distributed across the platform and motor subsystem. Brushless DC motors perform rotation of the mirror. Arduino Due board with built-in 32bit ARM core microcontroller Cortex-M3 CPU was chosen to be PAT computer and controls motors, collects data from sensors, calculates mirror position and provides the communication with the host computer. (Fig.4) 


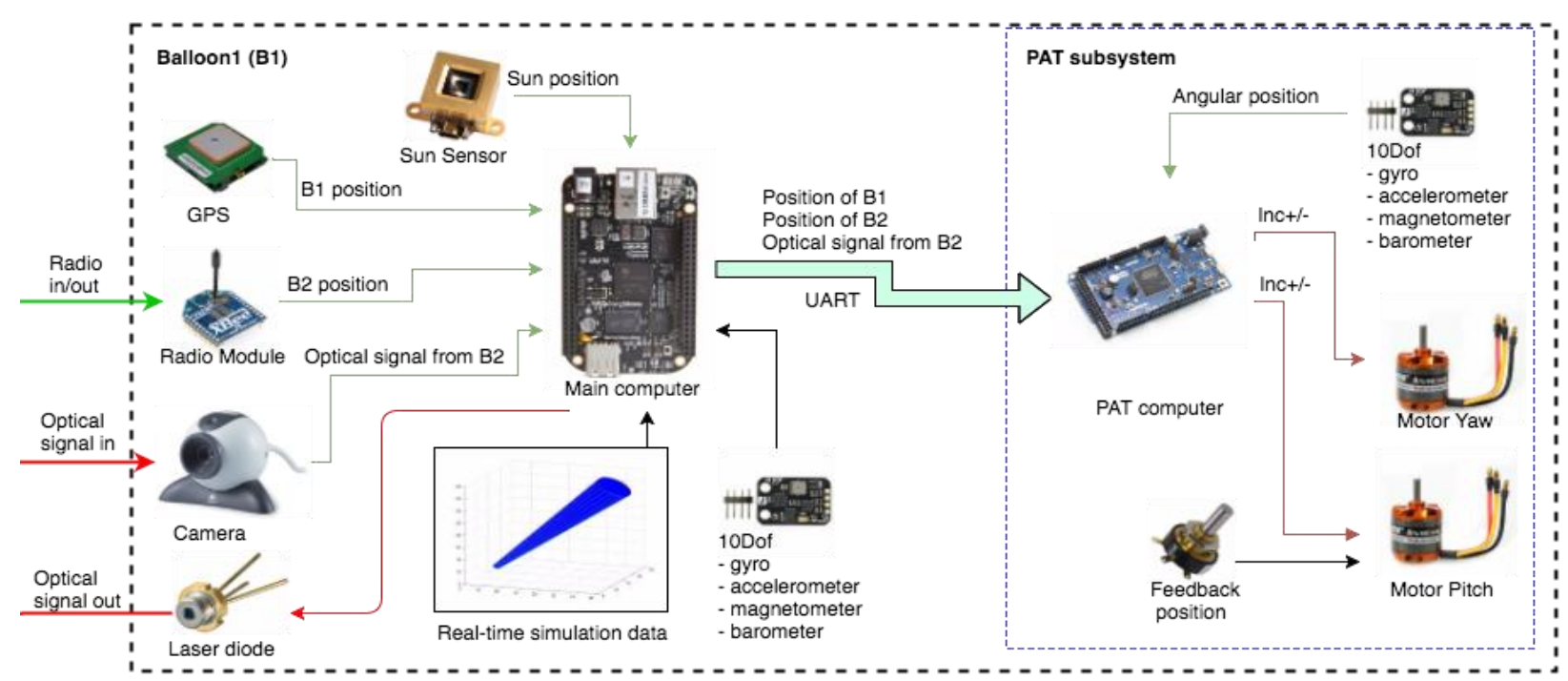

Fig.4. PAT system architecture

The exact definition of the orientation of the mobile robot is a critical task in the PAT system development. Accelerometer, gyroscope and magnetometer are installed on the platform in order to determine the orientation of it. The magnetometer is located as far as possible from motors and the metal parts of the telescope in order to minimize electromagnetic noise, affecting its performance. Another sensor with an accelerometer and a gyroscope is mounted on the mirror to determine its position. The potentiometer is fixed on the motor shaft to determine the yaw position of the mirror and the rotation angle of the motor. PAT computer performs data collection and processing from the sensors located on the PAT system (Fig.5).

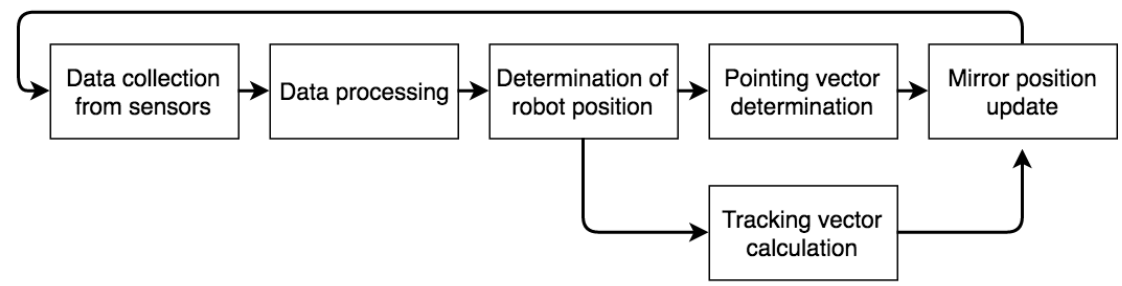

Fig. 5. PAT system representation as finite state machine

The developed control system consists of host computer, PID controller, and load (Fig.6). Pitch and yaw angle change in each cycle. The load consists of a mirror, the laser holder and 10dof sensor, which is placed on the mirror. The orientation of the mirror and the absolute rotation based on potentiometer data are fed to a microcontroller, which generates a sine wave PWM signal and controls the motor via the driver, as a feedback.

During the present work, the structure and drivers of the PAT systems have been developed. The structure consists of the mirror holder and frame. Mirror holder is fixed on the one side to the motor shaft and on the other - to laser metal holder. The frame, which is designed to the mirror holder, is fixed on the yaw motor shaft. 10dof sensor is attached to the mirror holder at the intersection of the two axes of rotation. Yaw motor is placed on the platform. The PAT system center of mass is located at the intersection of the axes of rotation of the engine in order to prevent vibrations.

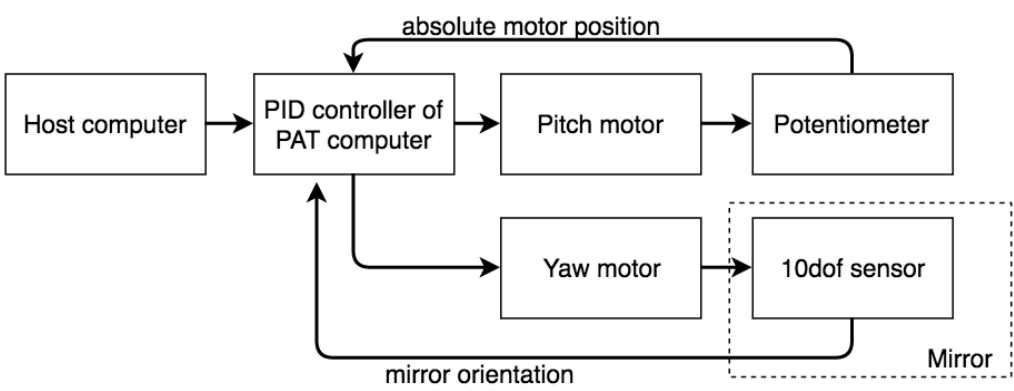

Fig. 6. PAT system algorithm

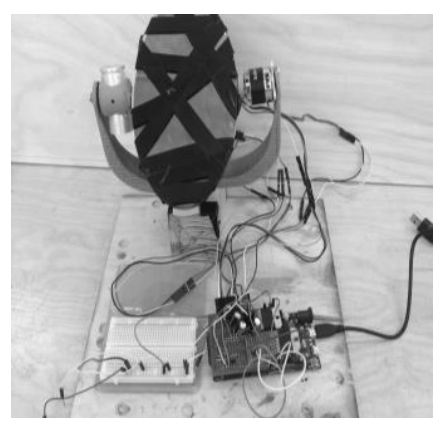

Fig. 7. PAT system design 


\section{Experimental prototype}

On this stage of the work, PAT subsystems, such as stabilization and attitude determination, the optical subsystem have been tested separately. The stabilization system was tested in the laboratory conditions using two PAT prototypes. The experimental scheme is shown in Fig.8. During the stabilization system test platforms were deflected at angles between 0 to 30 degrees and the accuracy of the system was determined.

Due to 10dof sensor measurement noise, mechanical misalignments in mirror mounting, imperfections of 3D printing, a center of mass offset the definition of the pitch angle (relative to the yaw angle) was less accurate. Thus, the error in the pitch angle determination was 4.3 degrees, and the yaw angle - $1.2 \mathrm{deg}$. Fig. 9 shows the changes in pitch and yaw angles, the control response of the system and for angular deviation of 5, 15, 20 and 30 degrees respectively. Pitch angle deviation included fast (40deg/s) and moderate $(10 \mathrm{deg} / \mathrm{s})$ rotation around $\mathrm{z}$-axis. The rotational speed was determined by using a gyroscope. Blue dots indicate the time when pointing error is less than 7 degrees, and pink dots indicate the time when pointing error is less than 4 degrees. Pointing accuracy value determined during the experiment was equal to 5.4 degrees at an angular displacement of $16 \mathrm{deg}$. Thus, within 40 seconds of the experiment, the number of connections between the two laser terminals was 6 and 20 with the beam divergence equal to 4 and 7 degrees respectively. The performance of the system was sufficient to ensure a data rate of $50 \mathrm{Mbs}$.
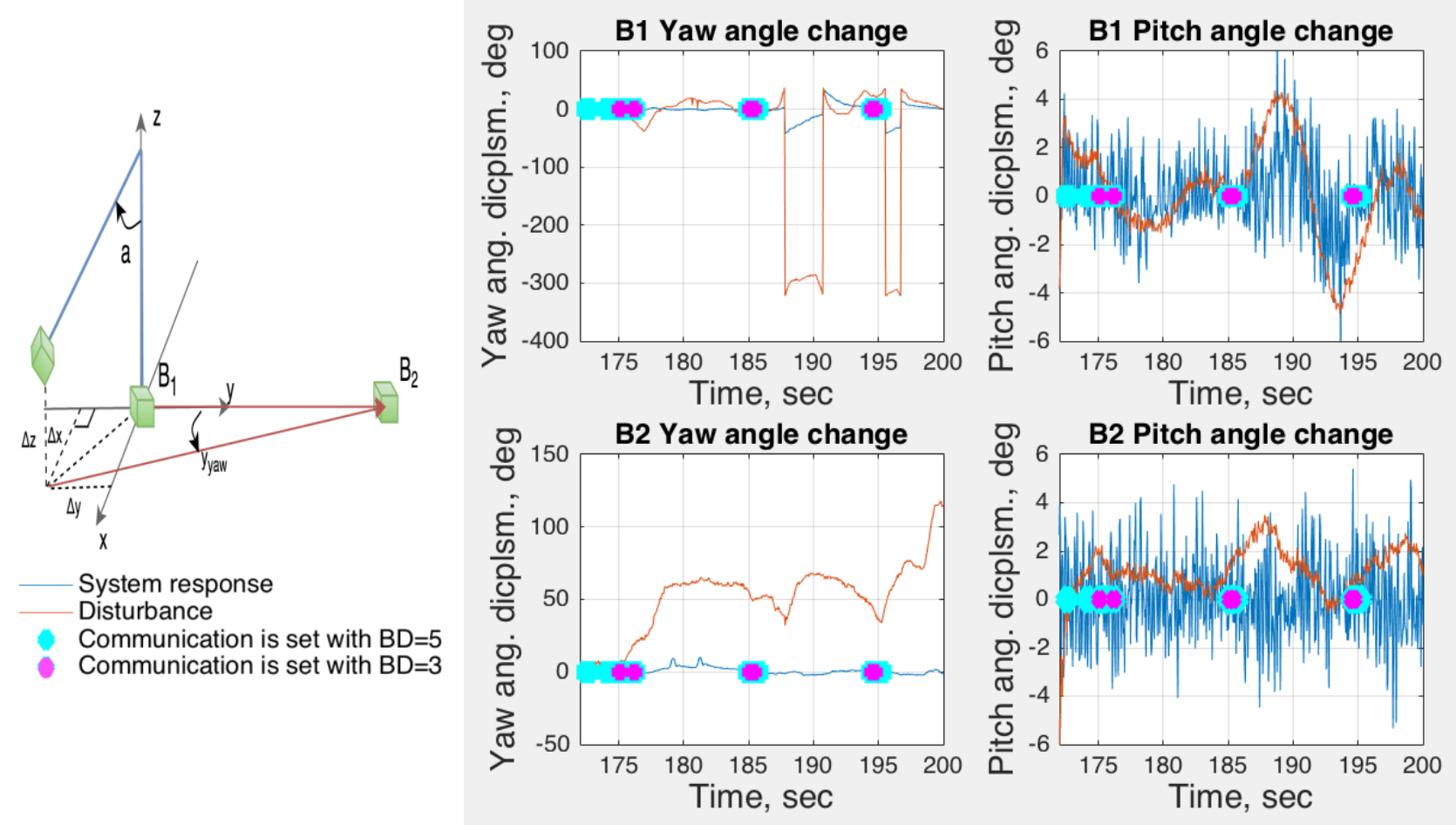

Fig.8. The experimental setup for Fig.9. Visualization of PAT system disturbances rejection capabilities at different the stabilization system testing angles of deflection in two planes and the allocation of time periods in which it is possible to establish optical communication.

\section{Conclusions}

In the case of mobile robots utilisation in extreme conditions, there is a significant need for the laser secure communication for the transmission of video streams between the mobile robots, robots and the repeater. Thus, this works' aim was to develop a laser terminal in order to provide the optical link between mobile robots. The work started with the literature review, which showed the incoming need in the development of laser communications for mobile robots operating in extreme conditions. Based on the derived system requirements and modelling of a group of mobile robots dynamics, the laser terminal concept, the orientation determination algorithm, pointing, acquisition and tracking (PAT) system, high-speed image processing algorithms have been developed. For the experimental laser terminal design proof of concept, the PAT system design was proposed, the control system and such subsystems, as the orientation determination and stabilisation, were developed. The low-level sensorless control of brushless motor was chosen and implemented together with PID controller; for the orientation determination the Magwick filter-Triad algorithm fusion was proposed. The necessary hardware and software (structural design, orientation algorithm, sensors processing, communication protocols, motor control algorithm, PID controller) were developed and the system was tested "on the table" through several iterations. As a result, the PAT system accuracy achieved 5 degrees, thus providing a data transfer rate close to $50 \mathrm{Mbs}$. In the next stages of work ways to assess and absorb vibrations shall be examined as well as its impact on the pointing accuracy and the final version of the hardware and software of the system shall be developed. 


\section{References}

[1] Chan, Vincent WS. "Free-space optical communications." Journal of Lightwave Technology 24.12 (2006): 47504762.

[2] Link: http://www.parabolicarc.com/2015/04/26/digital-solid-state-propulsion/

[3] NASA, "Small Spacecraft Technology - State of the art," Ames Research Center, Moffett Field, California, Mission Design Division, 2015. išpi

[4] Nakagawa, Keizo, and Akio Yamamoto. "Preliminary design of laser utilizing communications equipment (LUCE) installed on optical inter-orbit communications engineering test satellite (OICETS)." Photonics West'95. International Society for Optics and Photonics, 1995.

[5] Alluru, Seshupriya, and Janise McNair. "An optical payload for cubesats." (2010).

[6] Pryanichnikov VE, Bielich T. Vitsa D., B. Katalinich, Kirsanov KB, Jars SV Marzanov YS, Yu Poduraev, Helemendik RV Prysev E .A., Ugleshik A., Harin KV Development of educational technology and the associated laboratoryrobotarium. Information-measuring and operating systems, M .: Radio engineering. 2015, t.13, N7 - ISSN 2070-0814, S.7-25 (Пряничников В.Е., Биелич Т., Вицан Д., Каталинич Б., Кирсанов К.Б., Кувшинов С.В., Марзанов Ю.С., Подураев Ю.В., Хелемендик Р.В., Прысев Е.А., Углешик А., Харин К.В. Разработка образовательных технологий и сети ассоциированных лабораторий-роботариумов. Информационно-измерительные и управляющие системы, М.: Радиотехника. 2015, т.13, N7 - ISSN 2070-0814, C.7-25)

[7] Pryanichnikov, V. E., and V. P. Andreev. "Intellectulazation of special mobile robots, including return algorithm to a zone of stable RC." Proceedings of the XXI Int. Conference on Extreme Robotics, St. Peterburg: Poliectnika-service. 2010.

[8] Pryanichnikov, V. E., V. P. Andreev, and E. A. Prysev. "Group control of mobile robots, based on the nettechnologies." Proceedings of the Int. conference on Robotics for Security \& Space (Planet \& Earth rovers), St. Peterburg: Poliectnika service. 2010.

[9] Katalinic, Branko, et al. "Bionic Assembly System: hybrid control structure, working scenario and scheduling." Proceedings of 9th National Congress on Theoretical and Applied Mechanics, Brussels. 2012.

[10] Valentin, Pryanichnikov, and Shipovalov Egor. "Terrain Modeling for Mobile Robot Control Using Cross-Section Curves in Nested Multi-Resolution Grids." Annals of DAAAM \& Proceedings26.1 (2015).

[11] Kirsanov K., Levinsky B., Pryanichnikov V. Integrating software for intelligent robots // Informational-Measuring and Control Systems, Radiotechnika. 2009. V. 7. № 6. P. 35-43.

[12] Kirillchenko A.A., Pryanichnikov V.E., Rogozin K.V. Limits of validity and reliability of proofs. Scepticism in mathematics, functions, and traditions // Information-Measuring and Control Systems. 2013. V. 11. № 4. P. 57-65.

[13] Katsurin, Alexey. "Planning Trajectory of the Mobile Robot with a Camera." Annals of DAAAM \& Proceedings 26.1 (2015).

[14] Andreev, Victor, et al. "Training Situation Center Based On Three-Dimensional Virtual Studio for Distributed Mobile Robotics Laboratory." Annals of DAAAM \& Proceedings 26.1 (2015).

[15] Isaenko, Sergey, et al. "Simulation of Manipulator as a Part of Space Robotic System Weightlessness Device." Annals of DAAAM \& Proceedings 26.1 (2015).

[16] Ilyukhin, Yury, and Ruslan Kolesnichenko. "Impedance Control of High-Precision Geared Servo Drives With Two Motors for Technological Robots." Annals of DAAAM \& Proceedings 26.1 (2015).

[17] Andreeva, Victor, Pavel Pleteneva, and Yury Poduraeva. "The Method of Network Control of Robotic Systems of Different Models and Manufacturers."

[18] Filaretov, Vladimir, Dmitry Yukhimets, and Eduard Mursalimov. "The Universal Onboard Information-Control System for Mobile Robots." Procedia Engineering 100 (2015): 737-745. 